المجلة الدولية للدراسات التربوية والنفسية

International Journal of Educational \& Psychological Studies (EPS)

Journal Homepage: https://www.refaad.com/views/EPSR/Home.aspx

ISSN: 2520-4149 (Online) 2520-4130 (Print)

\title{
Adaptation, family cohesion and happiness among tenth-grade students in Irbid governorate
}

\author{
${ }^{1}$ Shuroog M. Maabreh, ${ }^{2}$ Anas R. Al-Masri
}

1,2 Department of Counseling and Family Reform, Jadara University, Jordan

2 dranas.almasri@hotmail.com

Received : 4/4/2020 Revised : 6/5/2020 Accepted : 29/5/2020 DOI : https://doi.org/10.31559/EPS2021.9.1.18

Abstract: This study aimed to identify the relationship between adaptation, family cohesion and happiness among tenth grade students in Irbid Governorate, and to gauge the differences between them according to gender, the level of mother's education, and the level of father's education, based on a sample of (381) students. The results of the study showed that there was a positive statistically significant relationship between adaptation, family cohesion, and degrees of happiness. The result also showed that there were statistically significant differences in feeling happy attributable to the gender variable and the level of the father's education, in favor of male variable whose educational level is less than the secondary education. The results showed that there were statistically significant differences attributable to the gender variable in family adaptation, and the differences were in favor of males. And there were statistically significant differences attributable to the variable level of mother's education in family adaptation; as well as there were statistically significant differences attributed to the variable level of father's education in all fields. The results showed that there was a statistically significant effect of happiness on cohesion and family adaptation, which means that increase degree in happiness, will lead to an increase in family cohesion and adaptation by $(0.0806)$.

Keywords: Family adaptation; family cohesion; happiness; adolescence; tenth grade students; Irbid Governorate.

\section{Introduction}

The contemporary challenges have directly influenced the family by the different levels of changes it brought to these families in terms of changing their beliefs, values, defining their identity and exposing them to new kinds of disturbance that affects the structure of the community. Therefore, various psychological and sociological studies have sought to address this serious issue as it led to the emergence of the phenomenon of family breakdown. Many statistics have shown that the ratio of divorce, juvenile delinquency and the crimes of delinquency, suicide, domestic violence have noticeably increased. Nevertheless, psychological and sociological studies dealt with this serious issue in a contradicting way. Where the first trend focuses on studying the negative aspects and the problems that disturb the family, the second trend focuses on the family positive aspect and how they can live a state of happiness, idealism and achieve quality (Bin Issa; Bousahla and Owaisi, 2013). Given the importance of family experiences for individual wellbeing and social adjustment, it is important to understand whether and how family functioning characteristics shape emotional experiences inside and outside the familial context. One such characteristic that has received attention as a predictor of well-being in the family is familial cohesion. Indeed, familial cohesion, defined as the degree of togetherness or closeness or emotional bonding that family members have toward one another, was found to be correlated with interpersonal well-being and satisfaction in adults. Also labeled closeness-caregiving, the most important elements of the concept of high cohesion include warmth, nurturance, time together, physical intimacy (affection), and consistency. Satisfaction with family bonds, which is related to cohesion, reflects the extent to which the need for cohesion or closeness in family relations is generally satisfied (Vandeleur; Jeanpretre; Perrez; Schoebi, 2009). Several studies have indicated that if the individual's family atmosphere is disturbed and suffers from family disintegration, it certainly leaves a clear indication on the children's personality and their interactions such as the study of Láng (2018) showed Family cohesion predicted affective aspects of well-being, whereas cognitive elements of well-being were 
predicted by family flexibility. The importance of the family's emotional and relational climate, predictability, and structured family functioning are highlighted as important contributors of adolescent well-being. Where (Johnson, Lavoie and Mahaney, 2000) study showed that the loss of cohesion in the family leads to feeling loneliness, social anxiety and avoiding social interaction outside the family.

Many psychologists have insisted on the Adolescence period to be a crisis; but Erikson believes that teenagers or young adults will gain moderated psychological balance if $s /$ he comes to know him/herself in the right time by learning to interact properly with the society through the experiences s/he has had. But, if s/he is lost in identity and is uncertain of her individual identity, s/he will not have psychological balance and will be facing identity crisis (Rahgozar and Yousefi, 2012). Margaret Mead (1983) discussed the psychological matters that an teenager encounters such as tensions, pressure, and pain that resulted from various factors of frustration and conflict; that he is exposed to in his life whether inside or outside his family, in his school or in his community indicating that the teenager suffers from anxiety, hesitation and pessimism. All these pressures reduce the level of his activity, enthusiasm and optimism. Adolescence is the period of significant changes and the harmony between the child's relationships with his parents. Most adolescents continue to feel intimate with their parents during that period, enjoy spending time with them, appreciate their opinions, and respect them as persons and as symbols of authority (Arnett, 1999).

Even a family with one adolescent is subject to a series of changes because of the adolescent's demands for more freedom. Generally speaking, the extent to which an adolescent succeeds in overcoming his stage of growth positively affects his family, while his failure leaves a negative impact on his family (Masselam; Marcus and Stunkard, 1990). However, the increasing tension between parents and their teenagers is centered on issues of a power struggle or conflict in areas such as chores, homework, curfew, dating, personal appearance and not about basic values, education or religion (Smetana, 1999). Additionally, adolescence is associated with increases in negative emotions (i.e. mood swings), these changes may affect the way teenagers deal with their parents which may lead their parents to underestimate or overestimate their needs and abilities (Steinberg and Silk, 2000). Changes in adolescent cognitive abilities can change the interpersonal dynamic between parents and adolescents; adolescents in this period think like adults. They are able to think abstractly, their reasoning becomes multidimensional and they come up with a new epistemic framework for family discussions. They seek to be treated like adults and they want to take part in family discussions that revolve around family affairs and its decision-making therefore they may challenge the method that the family currently uses in making decisions and may inquire about the rules and reasons for these decisions. Such challenges can severely affect parents as they may interpret these challenges as their son's rejection of their values, underestimating their decisions as parents, and they may feel pain when their adolescent's sons criticize the things they say or do. Consequently, these tensions may lead to an emotional distance between parents and teenagers that often reflected in the emergence of increased negative interactions between them, and decrease in positive interactions (Flanner; Torguati and Lindemeier, 1994). Adolescence is also characterized by the need for more independence and greater privacy as adolescents expect fewer restrictions, more opportunities for freedom and self-management. Notably, teenagers spend less time with their families during this stage; as they spend most of their time with their mates, their relationship with their peers becomes more important and influential, and they become less subject to parental control. They also have more freedom to movement more than when they were children (Such as: they can drive cars.). Although adolescents tend to welcome this new freedom, it makes parents more worried about them; parents in particular worry about their ability to monitor and control their adolescent's behavior, they fear for their adolescents 'safety such as: their concern for their inclusion in drug use, drinking alcohol, sexual activity and wrong use of the social network and the internet. Parents also find it difficult to reconcile with the fact that their teens prefer peer as secretors or as trusted people and choose to spend more time with peers than participate in family activities (Arnett, 1999).Sternberg and Skull (2000) emphasized the importance of establishing a new teens-parents balance that requires reviewing the child's relationship with his parents on one side, and modifying the nature of the relationship of parents with their children which shall (be) based on guiding and disciplining on the other hand(i.e. children) now teens.It is known that a teenager who grows up in a coherent family feels safe, enjoys a healthy growth that is represented in having self-confidence and trusting others, accepts goodness, avoids evil and enjoys great mental health. While a teenager who grows up in a dysfunctional family is subject to deprivation, frustration, and injustice in his relationship with his parents and siblings. He lives in turmoil, he goes through a disturbed psychological growth as he becomes subject to feeling guilt, self-despair, unsatisfied with himself and his life and he live(s) a misery life (Gallo and Troyelk, 2003). This is confirmed by Pettit; Bates; Doge and Meece (1999) who explained that a teenager who has a cohesive life with his family, his parents know where he is and what he does most of the time; they encourage his independence but at the same time they monitor his activities to ensure that he is safe. They achieve the right balance between respecting his right to privacy and protecting him from the dangers associated with teenage period. Rubin et al. (2004) suggests that adolescents raised by firm parents are of social adequacy and have good emotional tolerance compared with adolescents whose parents are authoritarian, lenient or ignored. Hence, adolescence may be the last opportunity for some

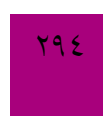

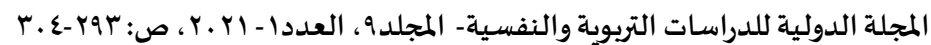


people to make changes in their ways of living by gaining a suitable psychological impact, and adolescence is an important period for the formation of lifestyle for the coming years.

Conducting studies in issues related to positive emotions such as happiness, love, entertainment, hope, companionship, gratitude and prestige, began to attract the attention of researchers in the nineties of the twentieth century, and one of the reasons for this delay is that psychological researchers spend most of their time trying to help people in overcoming their anger, fear and depression (Csikszentmihaly, 1999). Seligman (2004) categorized emotions into three categories: (1) Feelings that relate to the past, such as contentment, conviction, pride, and serenity. (2) Feelings that are associated with the present and are divided into two different categories: (a) physical pleasures or desires such as pleasure and warmth, joy and higher pleasures such as bliss, ecstasy, and rest; and (b) satisfaction resulting from activities such as reading, speaking, and camping. (3) Feelings that relate to the future include optimism, hope, confidence and faith. Psychologists consider the feeling of happiness as a significant indicator of mental health, and many psychologists who support the movement of positive psychology, or what is known as psychology of strengths, believe that feeling of happiness is an essential component of a healthy psychological and physical life (Al-Rabbai, 2014).

Carruther and Hood (2004) indicate that happy people are less likely to have family problems and diseases and are, therefore, they are more likely to lead an effective life than others.Many psychological studies have also addressed the characteristics of individuals with high mental happiness such as (DeNeve, 1999; Diener, 2000; lyubomirsky; King and Diener, 2005) that they revealed that individuals with high mental happiness are emotionally stable with a conscience alive, trusted by others, and able to take control over situations or try to control them. They also enjoy independence, positive relationships with others, have a goal to accomplish and are more self-acceptance. Although happy people also have a bad mood, but they are able to overcome quickly, and they have a high sense of good self-esteem, which is an indicator of their pleasant life. They have more ability than the unhappy persons to attract friends and partners and develop relationships that are suspended for a longer period. And when they marry, their marriage lasts longer. Fowler and Christakis (2008) found that when a person becomes happier within a few months; some of his friends become happier which indicates that happiness is obviously contagious. In fact, there is a mutual relation between happiness and relationships. Happiness promotes relationships, and relationships increase happiness. Momeni et al. (2011) found that happy people are kind and tend to help others when they need it, they have the ability to persist, in addition to be highly qualified and they can deal with the different life conditions and pressures effectively.

The definitions of happiness varied, Springer and Hauser (2006, p 1081) define happiness as a state of general satisfaction of an individual with himself and his life, his continuous pursuit to achieve his personal goals, his independence in defining the path of his life, his establishment of positive and mutually social relations with others. Happiness is not the opposite of unhappiness as it was confirmed by Argyle (1993, p. 24) who sees happiness as a reflection of the degree of satisfaction with life, or as a reflection of the frequency of occurrence of pleasant emotions and the intensity of these emotions. On the other hand, it is not completely opposite of misery. Happiness can be viewed from two aspects: happiness as a feature, which is the long emotional impact, Individuals with a high degree of satisfaction have a sense of contentment, they have an external or internal dynamic and vitality and a positive outlook. They have successful relationships, and they can enjoy their time in their own way. As for happiness as a state, it expresses the emotional state that the individual feels and expresses it in his own way in a specific situation (Al-Fangari, 2006).

By studying the previous research, the researchers found the scarcity of studies dealing with the nature of the relationship between adaptation, family cohesion and happiness, but there were some studies that dealt with the same variables as of this study in addition to other variables, including; Al Azab (2019) study that aimed to identify the effect of family characteristics (family size, income, the level of education of the parents, the age of the parents, the profession of the parents) on the degree of family cohesion among university students. The study sample consisted of (165) students. The results revealed a statistically significant effect of the family size variable on the two dimensions of cooperation, communication and the overall degree of cohesion in favor of smaller families, and the presence of a significant effect of the father's age variable on the dimensions of communication and flexibility, and the overall degree in favor of the older age group. The educational level of the parents, the professional status of the parents on all sub-dimensions and the overall degree of family cohesion. The results also showed that there was no effect of the variable (the mother's age, family income, the educational level of the parents, the professional status of the parents) on all sub-dimensions and the overall degree of family cohesion. Daradkeh (2019) discussed the relationship of family cohesion with emotional disorders among adolescent students in secondary schools. The study sample consisted of (545) male and female students. The results showed that the level of family cohesion came at a moderate level and that there were statistically significant differences for the level of family cohesion according to the gender variable and in favor of males, and according to the variable of childbirth and in favor of the middle order. The results also indicated a statistically significant relationship between the level of family cohesion and the level of emotional disorders among the sample members, and the dimensions of family cohesion that contribute in (62\%) to the level of emotional disorders in the sample members.Al-Sawafi (2019) conducted a study aimed to identify the level of psychological happiness

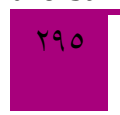

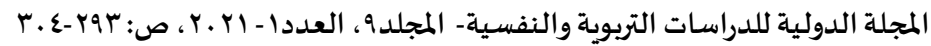


among a sample of the ninth grade students, to study the relationship between psychological happiness and the concept of self among the study sample, and to identify the level of significance of the differences in the answers of the members of the study sample on the psychological happiness scale according to the gender variable. The sample of the study consisted of (300) male and female students. The study found that the level of psychological happiness among the ninth-grade students was high, and that there was a positive correlation between the psychological happiness and the concept of self. And there was a statistically significant differences in the answers of the study sample on the psychological happiness scale according to the gender variable. Rahgozar and Yousefi, (2012) conducted a study aimed to study the effect Family's flexibility and cohesion on shaping the identity of students at Shiraz Branch, Islamic Azad University. The Causal Comparative method is applied to conduct the research and the statistical sample included 375 students, selected randomly from Azad university of Shiraz. The result indicated that family flexibility and cohesion affect identity of students positively, especially in terms of the two dimensions of exploration and commitment. Simon and Malanie (2011) conducted a study aimed to identify the relationship between eating habits of family meals (individual and collective) and their impact on family cohesion. The study sample consisted of (277) male and female adolescents from (95) families. The results of the study indicated that there was a positive relationship with a high positive relationship between having family meals collectively and family cohesion and adaptation. It also indicated a positive relationship between certified family meals, especially desserts, family adaptation and cohesion. Vandeleur; Jeanpretre; Perrez and Schoebi (2009) paper investigated whether higher cohesion and satisfaction with family bonds were associated with the daily experience of emotional well-being in varying social circumstances. Multilevel analyses revealed higher cohesion to be associated with well-being in fathers and adolescents, but not in mothers. Parents also reported higher well-being when with friends or colleagues than when alone. Uruk, Sayger, and Cogdal (2007) study aimed to identify the effect of adaptation and family cohesion on psychological trauma and psychological state among university students, the sample of the study consisted of (189) university students. The results showed that there was a high statistically significant relationship on the ability of adaptation and family cohesion with the symptoms of psychological trauma and psychological conditions in students alike. In 2006 a study was conducted by Lee; Herry and Kissinger aimed to determine the impact of parental treatment patterns on adolescent psychological adaptation. The sample of the study consisted of (185) male and female adolescents from high school students in Wisconsin state schools. The results revealed a statistically significant correlation between the patterns of family interaction, the concept of self and the status of academic control and achievement in adolescents, as adolescents whose positive family interaction style was characterized by a concept with a positive concept, an internal control center, and a higher level of achievement than adolescents whose family interaction was negative.

\section{The Study Problem}

The interest in the concept of adaptation, family cohesion and happiness has increased in the psychological field as it is considered one of the preventive processes that determine the adolescent's ability to adapt to the difficulties and stressful situations facing him in his life; hence the idea of this study, which is concerned with studying the characteristics of proper behavior to enable a teenager to live a healthy life in which he can achieve his ambitions, exploit his abilities to the fullest extent possible and to obtain self-satisfaction. The research also seeks to assist the adolescent to have faith in others, to change his negative thinking about himself and others to better see the world. With the constant scientific development in various areas of life, including precise study of human evolution through its various stages, psychologists have concluded that adolescence is one of the most significant developmental stages in a person's life .Therefore, it is necessary to address this stage by conducting scientific in the psychological, physical and social aspects studies. Since the tenth-grade students are a representative sample of all segments of Jordanian society, they represent a model of the Jordanian teenager who suffers from economic conditions, social, psychological, and political changes which drive them to search for happiness. The researchers also noticed that studies that were concerned with dealing with the relationship between adaptation, family cohesion and a feeling of happiness are rare, and through research and access - to the researchers' knowledge - no study was found linking between adaptation, family cohesion and a feeling of happiness, despite the importance of adaptation, family cohesion and the logical relationship that links them with the concept of happiness; and from this standpoint, this study attempts to bridge this gap.

\section{Study Hypotheses:}

1. There is no statistically significant correlation between the levels of family adaptation and the degrees of feeling happy among the tenth-grade students in Irbid Governorate.

2. There is no statistically significant correlation between the levels of family cohesion and the degrees of feeling happy among the tenth-grade students in Irbid Governorate.

3. There are no statistically significant differences between the averages of the overall grades on the happiness scale for the tenth-grade students in Irbid Governorate, due to the difference in the demographic variable (gender, mother's education level, and father's education level).

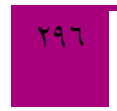


4. There are no statistically significant differences between the averages of the overall grades on the adaptation scale of and family cohesion among students in the tenth grade in Irbid Governorate, due to the difference in the demographic variable (gender, level of mother education, and level of father education).

5. A sense of happiness can be expected through the level of adaptation and family cohesion among tenth grade students in Irbid Governorate.

\section{Method}

\section{Study Population and Sample:}

The study population included all adolescent male and female students enrolled in government schools in the Qasbah Irbid district during the first semester of 2019-2020. The sample of the study consisted of (381) adolescent male and female students in public schools in the Kasbah of Irbid district; the table (1) shows distribution of the sample data according to the study variables.

Table (1): Frequencies and percentages according to the study variables

\begin{tabular}{|c|c|c|c|}
\hline Demographic variables & Categories & Frequency & percent \\
\hline \multirow[t]{2}{*}{ Gender } & Male & 201 & 52.8 \\
\hline & Female & 180 & 47.2 \\
\hline \multirow[t]{3}{*}{ Level of mother's education } & Less than secondary & 187 & 49.1 \\
\hline & Diploma & 88 & 23.1 \\
\hline & Undergraduate & 106 & 27.8 \\
\hline \multirow[t]{3}{*}{ Level of father's education } & Less than secondary & 227 & 59.6 \\
\hline & Diploma & 95 & 24.9 \\
\hline & Undergraduate & 59 & 15.5 \\
\hline \multicolumn{2}{|l|}{ Total } & 381 & 100.0 \\
\hline
\end{tabular}

\section{Study Tools:}

Family Adaptability and Cohesion Evaluation Scale-III: The Family Adaptability and Cohesion Evaluation Scale-III-1983; used by Halsa (2008) is a self-report measure that measures two basic dimensions of the family environment model: family cohesion and family adaptation. There are four Levels of adaptation within this model range from extreme bad adaptation to extreme high adaptation (There are four levels of family adaptability: rigid, structured, flexible, and chaotic). The two central levels (structured and flexible) are considered the balanced levels of family adaptability and the two extreme levels (rigid and chaotic) are considered the unbalanced levels of family adaptability. Also, there are four levels of family cohesion: disengaged, separated, connected, and enmeshed. Similar to that for family adaptability, the two central levels (separated and connected) are considered to be the balanced levels of family cohesion and the two extreme levels (disengaged and enmeshed) are considered to be the unbalanced levels of family cohesion. The scale consists of (20) items 10 items gauging the cohesion dimension and (10) items gauging the adaptation dimension, and five items measuring the coherence dimension with two paragraphs for each. These concepts are: (emotional bond - support - family limits - time and friends - and interest in- harmony). The adaptation dimension was represented by three concepts: (command control - system) each has two paragraphs. The roles and laws were set in for four paragraphs. The examiner required to read the sentences and determine the degree of frequency of this behavior in his family, depending on a scale ranging from (1) which means (never) to (5) which means(always). The relationship to the dimension of cohesion can be obtained through this scale by adding the marks of the individual items (and a sign of the dimension of adaptation) by adding the marital paragraphs.

Happiness scale: This scale was developed by Hills and Argyle (Hills and Argyle, 2002), which was developed on the Oxford Happiness Questionnaire / (OHQ); translation and codification of Al-Menshawi (2009). The scale consists of (29) items; each of them includes one sentence, where the examiner answers each of them to determine its applicability to it by choosing one of the following options: (Strongly agree - Agree - Reluctant Disagree - Strongly disagree), where five points is used to indicate strongly agree and one point for strongly disagree. The points are reflected (reversed) in the negative items. The overall degree of the happiness scale is extracted through the compulsory addition of the degree obtained by the student on each of the items of the scale, where each item is given a point ranging from one to five for the positive items. The overall score for the scale ranges between (29 - 145), where the happiness of the individual increases with the increase in the degree obtained on the scale. The scale has good psychometric indicators. The stability factor exceeds (0.91); it is also related to external Criteria not less than (0.85).

The reliability of the study tool: To confirm the reliability of the study tool, the test-retest method was verified by applying the scale, and it was re-applied after two weeks to a group from outside the study sample consisting of

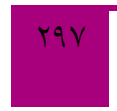


(30) member, and then Pearson correlation coefficient was calculated between their estimates both times. The reliability coefficient was also calculated by the method of internal consistency according to the Cronbach alpha equation. Table (2) shows the coefficient of internal consistency according to the Cronbach alpha equation and the test - retest reliability of the dimensions, and these values were considered appropriate for the purposes of this study.

Table (2): The internal consistency coefficient of the Cronbach alpha and the test - retest reliability

\begin{tabular}{|c|c|c|}
\hline Dimensions & Test-retest & Internal consistency \\
\hline Adaptation & 0.91 & 0.84 \\
\hline Cohesion & 0.86 & 0.81 \\
\hline Happiness & 0.90 & 0.82 \\
\hline
\end{tabular}

\section{Results}

\section{Results Related to the First Question:}

"There is no statistically significant correlation between the levels of family adaptation and the degrees of feeling happy among the tenth-grade students in Irbid Governorate". To verify the validity of the hypothesis, the Pearson correlation coefficient was calculated between the levels of family adaptation and the degrees of feeling happy among the tenth-grade students in Irbid Governorate as shown in Table (3).Table (3) shows that there is a statistically positive relationship between the levels of family adaptation and the degrees of feeling happy among the tenth-grade students in Irbid Governorate.

Table (3): Pearson correlation coefficient of the relationship between the levels of family adaptation and the degrees of feeling happy among the tenth-grade students in Irbid Governorate

\begin{tabular}{|c|c|c|}
\hline \multirow{2}{*}{ Happiness } & & Adaptation \\
\hline & Correlation coefficient t & $.230(* *)$ \\
\cline { 2 - 3 } & P value & .000 \\
\cline { 2 - 3 } & No. & 381 \\
\hline
\end{tabular}

\section{Results Related to the Second Question:}

" There is no statistically significant correlation between the levels of family cohesion and the degrees of feeling happy among the tenth-grade students in Irbid Governorate". To verify the validity of the hypothesis, the Pearson correlation coefficient was calculated between the levels of family cohesion and the degrees of feeling happy among the tenth-grade students in Irbid Governorate as illustrated in Table (4). Table (4) indicates that there is a positive and statistically significant relationship between the levels of family cohesion and the degree of feeling of happiness among the tenth-grade students in Irbid Governorate.

Table (4): Pearson correlation coefficient of the relationship between the levels of family cohesion and the degrees of feeling happy among the tenth-grade students in Irbid Governorate

\begin{tabular}{|c|c|c|}
\hline \multirow{2}{*}{ Happiness } & & Cohesion \\
\hline \multirow{2}{*}{} & Correlation coefficient t & $.358(* *)$ \\
\cline { 2 - 3 } & P value & .000 \\
\cline { 2 - 3 } & No. & 381 \\
\hline
\end{tabular}

\section{Results Related to the Third Question:}

" There are no statistically significant differences between the averages of the overall grades on the happiness scale for the tenth-grade students in Irbid Governorate, due to the difference in the demographic variable (gender, mother's education level, and father's education level).To confirm the hypothesis, the mean and standard deviations for the happiness scale were extracted for tenth-grade students in Irbid governorate according to gender variables, the mother's education level, and the father's education level as shown in table (5).

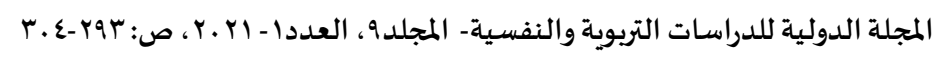


Table (5): Means and SD for the happiness scale for the tenth-grade students in Irbid governorate according to gender variables, the mother's education level, and the father's education level

\begin{tabular}{|c|c|c|c|c|}
\hline & & Means & SD & No. \\
\hline Gender & male & 3.20 & .225 & 201 \\
\hline \multirow{2}{*}{ mother's level of education } & female & 3.16 & .254 & 180 \\
& $\begin{array}{c}\text { Less than secondary } \\
\text { level }\end{array}$ & 3.20 & .263 & 187 \\
\cline { 2 - 5 } & Diploma & 3.19 & .207 & 88 \\
\hline \multirow{2}{*}{ Father's level of education } & Undergraduate & 3.13 & .215 & 106 \\
& $\begin{array}{c}\text { Less than secondary } \\
\text { level }\end{array}$ & 3.23 & .241 & 227 \\
\cline { 2 - 5 } & Diploma & 3.12 & .201 & 95 \\
\cline { 2 - 5 } & Undergraduate & 3.08 & .239 & 59 \\
\hline
\end{tabular}

Table (5) shows an apparent variation in means and the SD of the happiness scale for the tenth-grade students in Irbid Governorate due to the difference in the categories of gender variables, the mother's level of education, the father's level of education and to indicate the significance of the statistical differences between the arithmetic means. three-way anova was used as indicated in Table (6).

Table (6): Three-way anova analysis of the impact of gender, mother's level of education, and father's level of education on Happiness Scale for 10th Grade Students in Irbid Governorate

\begin{tabular}{|c|c|c|c|c|c|}
\hline Source of variance & SS & DF & MS & F value & P value \\
\hline Gender & .230 & 1 & .230 & 4.355 & .038 \\
\hline Mother's level of education & .173 & 2 & .087 & 1.640 & .195 \\
\hline Father's level of education & 1.594 & 2 & .797 & 15.102 & .000 \\
\hline Yrs. of experience & 19.789 & 375 & .053 & & \\
\hline Error & 21.772 & 380 & & & \\
\hline Total & 16.141 & 56 & & & \\
\hline
\end{tabular}

Table (6) showed that: (1) The are statistically significant differences $(\alpha=0.05)$ attributed to the effect of gender, where the $\mathrm{p}$ value $=4,555$ and with a statistical significance of $(0.038)$, the differences came in favor of males. (2) There are no statistically significant differences $(\alpha=0.05)$ due to the effect of the mother's level of education as the $p$ value $=1.640$ and with a statistical significance of (0.195). (3) The are statistically significant differences $(\alpha=0.05)$ attributable to the effect of the father's level of education, as the $p$ value $=15.102$ and with a statistical significance of $(0,000)$. To show the statistically significant of pair differences between the means, the Post Hoc of Schefft's method was used as shown in Table (7).

Table (7): The Post Hoc comparisons of Schefft's method to the effect of the father's level of education on Happiness

\begin{tabular}{|c|c|c|c|c|}
\hline & Means & $\begin{array}{c}\text { Less than } \\
\text { secondary level }\end{array}$ & Diploma & Undergraduate \\
\hline Less than secondary level & 3.23 & & & \\
\hline Diploma & 3.12 & $.11^{*}$ & & \\
\hline Undergraduate & 3.08 & $.15^{*}$ & .04 & \\
\hline *P value at $(\boldsymbol{\alpha}=\mathbf{0 . 0 5 )}$
\end{tabular}

Table (7) shows that there are statistically significant differences $(\alpha=0.05)$ between less than secondary level on the one hand and both diploma and university and the differences came in favor of less than secondary level.

\section{Results of the Fourth Question:}

" There are no statistically significant differences between the averages of the overall grades on the adaptation scale of and family cohesion among students in the tenth grade in Irbid Governorate, due to the difference in the demographic variable (gender, level of mother education, and level of father education)". To answer this question, the means and SD for the adaptation and family cohesion scale among tenth grade students in Irbid Governorate were extracted according to gender variables, the level of mother education, and the level of father education as illustrated in table (8). 
Table (8): Means and SD for the adjustment and family cohesion scale among tenth grade students in Irbid Governorate according to gender variables, the level of mother education, and the level of father education

\begin{tabular}{|c|c|c|c|c|c|c|}
\hline & & \multicolumn{2}{|c|}{ Cohesion } & \multicolumn{2}{|c|}{ Adaptation } & \multirow[t]{2}{*}{ No } \\
\hline & & Means & SD & Means & SD & \\
\hline \multirow[t]{2}{*}{ Gender } & Male & 3.52 & .538 & 3.98 & .427 & 201 \\
\hline & Female & 3.55 & .541 & 3.86 & .479 & 180 \\
\hline \multirow{3}{*}{$\begin{array}{l}\text { Mother's level of } \\
\text { education }\end{array}$} & Less than secondary & 3.54 & .573 & 3.92 & .470 & 187 \\
\hline & Diploma & 3.56 & .522 & 4.04 & .340 & 88 \\
\hline & Undergraduate & 3.51 & .494 & 3.84 & .498 & 106 \\
\hline \multirow[t]{3}{*}{ Father's level of education } & Less than secondary & 3.67 & .529 & 4.02 & .430 & 227 \\
\hline & Diploma & 3.51 & .371 & 3.86 & .343 & 95 \\
\hline & Undergraduate & 3.09 & .569 & 3.64 & .566 & 59 \\
\hline
\end{tabular}

Table (8) shows an apparent variation in the means and standard deviations of the adaptation and family cohesion scale among students of the tenth-grade in Irbid Governorate due to the difference in the categories of gender variables, the level of mother education, the level of father education and to indicate the significance of the statistical differences between the means the Three-way anova analysis was used as indicated in Table (9).Table (9) indicates that: (1) There are statistically significant differences $(\alpha=0.05)$ attributable to the effect of gender on adaptation and there are no statistically significant differences $(\alpha=0.05)$ in cohesion and the differences were in favor of males. (2) The are statistically significant differences $(\alpha=0.05$ attributable to the effect of the mother's level of education on adaptation and there are no statistically significant differences $(\alpha=0.05)$ in coherence as shown in Table (9). There are statistically significant differences $(\alpha=0.05)$ attributed to the effect of the father's level of education in all fields, and to show the statistically significant differences between the arithmetic averages and the pair comparisons the Post Hoc of Schefft's method was used as shown in Table (10). As indicated in Table (9) there are statistically significant differences $(\alpha=0.05)$ between diploma and university, and the differences were in favor of the diploma. Table (10) clearly indicates that there are statistically significant differences $(\alpha=$ 0.05 ) between undergraduate on one side and less than secondary and diploma, on the other hand, differences came in favor of both less than secondary and diploma in cohesion and adaptation.

Table (9): The Three-way anova analysis for the effect of mother's level of education, father's level of education on the

\begin{tabular}{|c|c|c|c|c|c|c|}
\hline $\begin{array}{c}\text { Source of } \\
\text { variance }\end{array}$ & dimensions & SS & DF & MS & F-value & P-value \\
\hline Gender & Cohesion & .204 & 1 & .204 & .814 & .367 \\
\hline & Adaptation & 2.712 & 1 & 2.712 & 15.384 & .000 \\
\hline $\begin{array}{c}\text { Other's level of } \\
\text { education }\end{array}$ & Cohesion & .510 & 2 & .255 & 1.016 & .363 \\
\hline & Adaptation & 2.403 & 2 & 1.201 & 6.813 & .001 \\
\hline $\begin{array}{c}\text { Father's } \\
\text { level of } \\
\text { education }\end{array}$ & Cohesion & 16.063 & 2 & 8.031 & 31.992 & .000 \\
\hline & Adaptation & 9.942 & 2 & 4.971 & 28.194 & .000 \\
\hline Error & Cohesion & 94.141 & 375 & .251 & & \\
\hline Total & Adaptation & 66.116 & 375 & .176 & & \\
\hline & Cohesion & 110.483 & 380 & & & \\
\hline
\end{tabular}

Table (10): The Post Hoc of Schefft's method to the effect of the mother's level of level on adaptation

\begin{tabular}{|c|c|c|c|c|c|}
\hline & & Means & Less than secondary & Diploma & Undergraduate \\
\hline Adaptation & $\begin{array}{c}\text { Less than } \\
\text { secondary }\end{array}$ & 3.92 & & & \\
\cline { 2 - 7 } & Diploma & 4.04 & .12 & & \\
\cline { 2 - 7 } & Undergraduate & 3.84 & .08 & $.19^{*}$ & \\
\hline
\end{tabular}

*P value at $(\alpha=0.05)$

Table (11): The Post Hoc of Schefft's method to the effect of the father's level of level on adaptation

\begin{tabular}{|c|c|c|c|c|c|}
\hline \multirow{4}{*}{ Table (11): The Post Hoc of Schefft's method to the effect of the father's level of level on adaptation } \\
\hline \multirow{3}{*}{ Cohesion } & Means & $\begin{array}{c}\text { Less than } \\
\text { secondary }\end{array}$ & Diploma & Undergraduate \\
& Less than secondary & 3.67 & & & \\
\cline { 2 - 6 } & Diploma & 3.51 & .15 & & \\
& Undergraduate & 3.09 & $.58^{*}$ & $.42^{*}$ & \\
\hline \multirow{2}{*}{ Adaptation } & Less than secondary & 4.02 & & & \\
& Diploma & 3.86 & .16 & & \\
\cline { 2 - 6 } & Undergraduate & 3.64 & $.39^{*}$ & $.22^{*}$ & \\
\hline
\end{tabular}

*P value at $(\alpha=0.05)$ 


\section{Results of the Fifth Question}

" Happiness can be expected through the level of adaptation and family cohesion among tenth-grade students in Irbid Governorate". To examine this hypothesis, simple linear regression was used, and the results were as follows:First: cohesion: The results indicate that there is a statistically significant effect of happiness on cohesion, where the correlation coefficient ( $(R=0.358$, which indicates a statistically significant correlation relationship between happiness and cohesion), the value of the coefficient determination $(\mathrm{R} 2=0.128)$, which indicates that happiness has explained $12.8 \%$ of the coherence variance, and the value of $(\mathrm{F}=55.592)$ was at a confidence level equal to $(\mathrm{sig}=0.020)$ and this confirms the significance of the regression at the significance level of $(\alpha<0.05)$. It can be noted from the table of coefficients that the values of (B) at (happiness) have reached (0.806) and that the value of $(t)$ was (7.456) and with a statistical significance of (0.000), which indicates that this effect is significant and this means that an increase in happiness by one point will result to increase the cohesion by (0.0806).Second: adaptation: As shown in the above table there is a statistically significant effect of happiness on adaptation, where the correlation coefficient $(\mathrm{R}=0.230$, which indicates a statistically significant correlation relationship between adaptation and happiness, it has been shown that the value of the coefficient determination $(R 2=0.053)$, which indicates that happiness was explained by a ratio of $5.3 \%$ of variance in adaptation, as the value of $(\mathrm{F}=21.201)$ at a confidence level is equal to $(\mathrm{sig}=0.020)$ and this confirms the significance of the regression at the significance levelof $(\alpha<0.05)$.Table (11) of the coefficient shows that the values of (B) at the dimension of (happiness) have reached $(0.806)$ and that the value of $(t)$ was $(7.456)$ and with a statistical significance of $(0.000)$, which indicates that this effect is significant and this means that the increase in happiness by one point will increase the adaptation by (0.0806).

Table (12): Results of the simple linear regression analysis of the effect of happiness on both adaptation and family cohesion

\begin{tabular}{|c|c|c|c|c|c|c|c|c|c|c|}
\hline & \multicolumn{2}{|c|}{ Model summary } & \multicolumn{3}{|c|}{ ANOVA } & \multicolumn{5}{c|}{ Coefficient } \\
\cline { 2 - 10 } & $\mathrm{R}$ & $\mathrm{R} 2$ & $\mathrm{~F}$ & $\mathrm{DF}$ & $\begin{array}{c}\text { Sig. } \\
\mathrm{F}\end{array}$ & variance & $\mathrm{B}$ & Error & $\mathrm{T}$ & $\begin{array}{c}\text { Sig. } \\
\mathrm{t}\end{array}$ \\
\hline Cohesion & 358 & .128 & 55.592 & 1 & .000 & Happiness & .806 & .108 & 7.456 & .000 \\
\hline Adaptation & 230 & .053 & 21.201 & 1 & .000 & Happiness & .439 & .095 & 4.604 & .000 \\
\hline
\end{tabular}

\section{Discussion of Results}

The researchers believe that the results are logical; they are consistent with the point of the psychological analysis theory, which confirms that human stability is a physiological stability stems from the satisfaction of instincts. Therefore, for Freud, most people are somewhat neurotic, and that emotional stability is an ideal thing, where conflict and anxiety are inevitable matters for a human. Freud has overstressed on the conflict that takes place between personality systems, which is the cause of the disturbance of psychological stability (Ali and Salman, 2013); the adolescent as considered by the psychological analysis is the outcome of the process of family learning and the environment. If these forces were moderate, the teenager becomes happy but if it is harmful the teenager feels unhappy. Generally, the teenager is shaped by the experiences he is exposed to, becoming good or bad depends on the quality of his experiences (Suqer and Al Bardisi, 2019). The results are consistent with Maslow's point of view in which he confirms that a human being has a fundamental nature, which is either to be a benevolent or of a neutral nature, but it is not evil. And that the healthy growth is based on achieving this nature towards maturity in addition to having a sound environmental condition, as the unhealthy environment impedes the individual and does not allow him to fulfill his desires, aspirations and choices; it may make him vulnerable to mental health collapse. Maslow also indicated that there is a set of needs that a person seeks to fulfill and that a person who cannot satisfy his needs is unable to think in a logical way which leads to psychological tension or instability (Zubeidi and Obeidi 2011). This study also corresponds with the behavioral theory in terms of that cohesion, adaptation and happiness are achieved through the individual's awareness of all the conditions that lead to the creation of the unstable behavior, in addressing and recording the behavior and the related conditions to promote the important alternative (Mubarak, 2008). Argyle (1993) also stressed on the impact of the network of social relations on feeling happy. He explained that an individual can achieve his desires only through his social circle and that the appropriate climate within the family is a psychological and healthy environment for growth that allows the teenager to obtain the necessary affection from his parents. The nature of this relation results in a calm and stable life averting them from being subjected to psychological and emotional disturbances. Therefore, a positive understanding by the family of the nature of adolescence would lead adolescents to optimal social and psychological compatibility. This explains the relationship between adaptation, family cohesion and a sense of happiness.The researchers attribute the result of the nonexistence of statistically significant differences attributable to the effect of the mother's education level on cohesion to the fact that the mother is half of society and the core of social life, as she is the main supervisor of all her family's affairs and she is the only one that makes

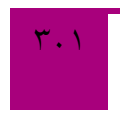


it coherent and stable. The mother's educational level does not affect the stability and cohesion of her family. The result of this can also be attributed to the educational characteristics of the study sample, as the percentage of educated mothers was nearly close to the other different educational levels, which means that the mothers are mostly educated. This fact increases their opportunity to obtain sufficient awareness of the dimensions of family adaptation and its importance to society and thus increases their opportunity to implant its manifestations in the souls of her children through the different stages of upbringing, to represent a general behavior for individuals in which a mother with an educational level does not differ from the other.The researchers explain the result of the statistically significant differences attributable to the effect of gender on adaptation that came in favor of males, that male students prefer a coherent family due to their frequent exit to real life, their awareness of the degree of problems, psychological pressures and emotional disturbances experienced by youth in societies nowadays and the large number of family disintegration that Arab societies suffer from. The researchers attribute the result of the statistically significant differences attributable to the impact of the mother's level of education and the father's level of education on adaptation to the impact of globalization and the various social means on parents that they have increased their awareness about the appropriate methods of bringing up their children especially the characteristics of a happy and successful family who are able to raise a teenager who is free from emotional disturbances.

\section{Recommendations:}

Considering the results of the current study, the researchers recommend:

1. Providing appropriate mechanisms and support to the family and the school which includes promoting family adaptation.

2. Expanding the scope of the research to include all governorates of the Hashemite Kingdom of Jordan, and with different age groups.

3. Holding a scientific conference on adaptation, family cohesion and psychological happiness.

4. Establishing educational programs for Jordanian families that explain the importance of the family environment and its impact on family members, and the need for parents to pay attention to providing a family atmosphere for children.

5. Carrying out specialized training sessions for educational counselors related to family sciences in the family context.

6. Field training plans and programs for family planning and counseling for the undergraduate stage include courses and practical training related to the use of family counseling interventions in the school context.

\section{Suggested Future Research}

1. Conduct studies on family cohesion and its relationship variables (such as the level of ambition, creativity, emotional stability, self-esteem, social intelligence, emotional intelligence, cultural intelligence, anxiety, and depression).

2. Conducting a study on parental separation and its effect on family cohesion and adjustment among adolescents.

3. Conduct correlative studies and compare the level of family cohesion among families of individuals with disabilities and families of ordinary individuals.

4. Conducting a study on aggressive behavior and its relationship to the level of family cohesion among different samples of students.

5. Conducting a study on self-esteem and its relationship to family cohesion among students.

6. Conducting a study on family cohesion and its relationship to emotional abuse among students.

\section{References}

[1] Al Nayal, M \& Ali, M. (1995). "Happiness and its relationship to some psychological and personal variables among a sample of elderly and elderly women". Journal of Psychology, (36): 422-40.

[2] Al Rabbai, S, Y. (2014). "Feeling happy and its relationship to the five major factors of personality among a sample of Damascus University students", Master's Thesis in Educational Psychology, Faculty of Education - Department of Psychology, Damascus University, Syria.

[3] Al-Azab, S, A. (2019). "Family cohesion as perceived by university students in the light of some family characteristics", The Arab Journal of Arts and Humanities, (8): 309-332.

[4] Al-Enazi, F O. (2001). "Feeling happy and its relationship to some personality traits, a correlative study between males and females", psychological studies series, 3 (11), 301-377.

[5] Al-Fangari, H, A. (2006). "Happiness between positive psychology and mental health". Cairo: Al-Ikhlas Institution for Printing and Publishing.

[6] Ali, W, \& Salman, Kh. (2013). "Existential anxiety and its relationship to emotional equilibrium for middle school

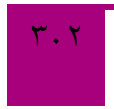

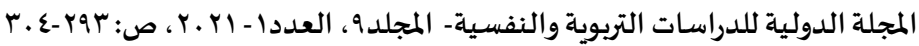


students". The Journal of Human Sciences, (19), 213-228.

[7] Al-Menshawi, S, J, M. (2009). "The relationship between happiness and emotional intelligence among a sample of Jordanian teenagers". Unpublished Master Thesis, Amman Arab University, College of Higher Education and Psychological Studies, Amman - Jordan.

[8] Al-Sawafi, M, N, S. (2019). "Psychological happiness and its relationship to the concept of self among ninth grade students in Wilayat Al-Mudaibi, Sultanate of Oman". Journal of Educational and Psychological Sciences - The Arab Journal for Science and Research, 10(3): 162-182.

[9] Al-Zubeidi, H; \& Al-Obeidi, Sh. (2011). "Measuring emotional balance and its relationship to achieving the goals of the gifted". The Arab Scientific Conference for the Welfare of the Gifted and Talented - Giftedness and Creativity are important milestones in peoples 'lives, Arab Council for the Gifted and Talented, Jordan, (11): 613-654.

[10] Argyle, M. (1993). "The psychology of happiness. Translated by Faisal Abdul Qadir Youssef, Knowledge World (175)", National Council for Culture, Arts and Letters, Kuwait.

[11] Arnet, J.J. (1999). "Adolescent storm and stress, reconsidered". American Psychologist, 54(5),317-326. https://doi.org/10.1037/0003-066x.54.5.317.

[12] Bin Issa, M,; Bousahla, E; \& Owaisi. (2013). "The Algerian family in light of the reproduction of the ingredients of family quality". The Second National Forum on: Communication and Quality of Life in the Family, 9-10 February 2013, Kassadi University Mirbah and Ouargla, College of Humanities and Social Sciences - Department of Social Sciences.

[13] Carruthers, C.P; \& Hood, C.D. (2004). "The Power of the positive”, Therapeutic Recreation Journal, 38 (2): $225-245$.

[14] Daradkeh, S, A, E. (2019). "The relationship of family cohesion with emotional disorders in exhausted students in high school", Journal of Educational science studies, 46(2): 565-586.

[15] Deneve, K.M. (1999). "Happy as an extraverted clam? The role of personality for subjective wellbeing". Current Directions in Psychological Science, 8(5): 141-144. https://doi.org/10.1111/1467-8721.00033.

[16] Diener, E. (2000). "Subjective well-being”. American Psychologist, 55: 34-43.

[17] Erica, W.; Simon,S., \& Melanie,W.(2011). "Examining the relationship between family meal frequency and individual dietay Intake: Does family cohesion role?". Journal of Nutrition Education and Behavior, 43(4):229-232. https://doi.org/10.1016/j.jneb.2010.03.009.

[18] Flanner, D.J., Torquati.J.C. \& Lindemeier, L. (1994). “The Method and meaning of emotional expression and experience during adolescence". Journal of Adolescent Research, 9(1): 8-27. https://doi.org/10.1177/074355489491003.

[19] Fowler,J .H., and Christakis,N.A.(2008). Dynamic spread of happiness in a large social network: Longitudinal analysis over 20 years in the framinghain heart study, British Medical Journal, 337, 92338.

[20] Gallo, L.C \& Troyelk. W. M. (2003). "Marital staut and quality in middle- aged women: Assosiations with leves and trajectories of cardiovascular risk factors". Health psychology, 22(5): 453-463. https://doi.org/10.1037/02786133.22.5.453.

[21] Hassouna, Gh, H. (2002). "Family compatibility of married students and its relationship with some variables", unpublished Master Thesis - Ain Shams University, Cairo, Egypt.

[22] Johnson, H.; 'Lavole, C., \& Mahoney,M. (2000). "Interparental conflict and family cohesion: predictors of loneliness, social anxiety, and avoidance, conflict (Psychologlogy), anxiety”. Journal of adolescent Research,16: 3,304-319.

[23] Láng, András. (2018). "Family Structure, Family Functioning, and Well-Being in Adolescence: A Multidimensional Approach". International Journal of Humanities and Social Science, 8 (2): 24-31.

[24] Lyubomirsky,S. King, L.L; \& Diener, E.(2005). "The benefits of frequent positive affect: Does happiness lead to success?". Psychological Bulletin, 131(6): 803-855. https://doi.org/10.1037/0033-2909.131.6.803.

[25] Mahmoud, M, I. (2006). “Adolescence”. Arab Society Library, Jordan.

[26] Masselam, V. S; Marcus, R.F. \& Stunkard, C.L. (1990). "Parent adolescent communication, family functioning and school performance". Adolescence, 99: 725-737.

[27] Mead, M.C. (1983). Male and female, NewYork: Dell.

[28] Momeni, M.; Kalali. N.; Anvari, M.; Raoofi, Z. \& Zarrineh, A. (2011). "What kind people are the happiest? An empirical study", International Review of Business Research papers, 7(3), 42-54.

[29] Mubarak, S, S. (2008). "Emotional equilibrium and its relationship to self-concept among distinguished students and their regular peers". Research Journal of the College of Basic Education, 7 (2), 65- 91.

[30] Pettit, G.S.; Bates, J.E; Dodge, K.A. \& Meece, D.W. (1999). "The impact of after-school peer contact on early adolescent extemalizing problems is moderated by parental monitoring, perceived neighborhood safety, and prior adjustment". Child Development, 7(3): 768-778. 
[31] Rahgozar, H, and Yousefi, S. (2012). The Impact of Family Cohesion and Flexibility on University Students' Identity: The Case of Shiraz Branch, Islamic Azad, Asian Social Science, 8 (2), 95-103.

[32] Rubin, K.H.; Dwyer, K.M.; Booth-laforce, C.; Kim, A.H.; Burgess, K. \& Rose-Krasnor, L. (2004). "Attachment, Friendship, and psychosocial functioning in early adolescence's". Journal of Early Aolescence, 24(4), 326-356. https://doi.org/10.1177/0272431604268530.

[33] Seligman, P. (2004). “Can happiness be taught?”. Daedal us Journal, 3(2), PP.1-59.

[34] Smetana, J.C. \& Gaines, C. (1999). "Adolescent-parent conflict in middle-class African American families". Child Development, 70(6): 1447-1463. https://doi.org/10.1111/1467-8624.00105.

[35] Springer, K \& Hauser, R. (2006). Au assessment of the construct validity of Ryffs Scales of psychological well-being: Method mode and measurement effects, Social Science Research, 35(4): 1080-1102. https://doi.org/10.1016/j.ssresearch.2005.07.004.

[36] Uruk, A., Sayger, T. and Cogdal, P. (2007). "Examining the influence of family cohesion and adaptability on trauma and psychological well-being". Journal of college Students, 22(2): 51-63. https://doi.org/10.1300/j035v22n02_05.

[37] Vandeleur, C. L Jeanpretre, N.; Perrez. M.; Schoebi. D. (2009). "Cohesion, Satisfaction with Family Bonds, and Emotional Well-Being in Families with Adolescents". Journal of Marriage and Family, 71 (2009): 1205 - 1219. https://doi.org/10.1111/j.1741-3737.2009.00664.x. 